\title{
On the Lightning Electromagnetic Fields due to Channel with Variable Return Stroke Velocity
}

\author{
M. Izadi, ${ }^{1,2}$ M. Z. A. Ab Kadir, ${ }^{1}$ and M. Hajikhani ${ }^{1}$ \\ ${ }^{1}$ Centre for Electromagnetic and Lightning Protection Research (CELP), Faculty of Engineering, University Putra Malaysia, \\ (UPM), 43400 Serdang, Selangor, Malaysia \\ ${ }^{2}$ Department of Electrical Engineering, Islamic Azad University, Firoozkooh Branch, 3981838381 Firoozkooh, Iran
}

Correspondence should be addressed to M. Izadi; aryaphase@yahoo.com

Received 1 October 2014; Accepted 30 January 2015

Academic Editor: Xiao-Qiao He

Copyright (C) 2015 M. Izadi et al. This is an open access article distributed under the Creative Commons Attribution License, which permits unrestricted use, distribution, and reproduction in any medium, provided the original work is properly cited.

\begin{abstract}
Numerical field expressions are proposed to evaluate the electromagnetic fields due to the lightning channel with variable values of return stroke velocity. Previous calculation methods generally use an average value for the return stroke velocity along a lightning channel. The proposed method can support different velocity profiles along a lightning channel in addition to the widely used channel-base current functions and also the general form of the engineering current models directly in the time domain without the need to apply any extra conversions. Moreover, a sample of the measured lightning current is used to validate the proposed method while the velocity profile is simulated by the general velocity function. The simulated fields based on constant and variable values of velocity are compared to the corresponding measured fields. The results show that the simulated fields based on the proposed method are in good agreement with the corresponding measured fields.
\end{abstract}

\section{Introduction}

Lightning is an important natural phenomenon that can affect power lines. Induced voltages are a major effect of lightning on distribution lines that can be created by coupling between the electromagnetic fields of the lightning and the power line [1-5]. Therefore, the evaluation of electromagnetic fields associated with lightning is an important objective when considering lightning induced voltages and setting an appropriate protection level for power systems. Several studies have been undertaken to estimate the electromagnetic fields due to a lightning channel [6-11]. Such studies depend on the lightning channel parameters, the geometrical parameters, channel shape, channel condition, and the ground conductivity parameters. Among the different channel parameters, the return stroke velocity is an important variable for the evaluation of lightning electromagnetic fields [10, $12,13]$, and this is usually entered into field calculations as an average value of velocities at different heights along a lightning channel, with a typical value between $c / 3$ and $2 c / 3$ ( $c$ is speed of light in free space) [14].
On the other hand, some experimental work has been carried out to measure the return stroke velocity at different heights along a channel where the velocity is measured as a height-dependent variable [14-17]. Therefore, the variation of velocity along a lightning channel can have an effect on the values of the lightning electromagnetic fields. In this study, numerical field expressions are proposed to evaluate lightning electromagnetic fields based on a channel with variable values of return stroke velocity directly in the time domain. Likewise, the proposed method is applied to a typical current sample whereby the corresponding return stroke velocity function is used for considering the velocity profile along a lightning channel. Further, the simulated fields are compared to the corresponding fields based on a constant value of velocity and the results are discussed accordingly. The proposed method can support a wide range of velocity profiles along the channel, along with various current functions and current models directly in the time domain without the need to apply any extra conversions. The basic assumptions in this study are expressed as follows. 
TABLE 1: $P\left(z^{\prime}\right)$ and $v$ for six engineering current models based on (3).

\begin{tabular}{|c|c|c|}
\hline Model & $P\left(z^{\prime}\right)$ & $v$ \\
\hline BG (Bruce-Golde model) [18] & 1 & $\infty$ \\
\hline TCS (traveling current source model) [19] & 1 & $-c$ \\
\hline TL (transmission line model) [9] & 1 & $v_{f}$ \\
\hline $\begin{array}{l}\text { MTLL (modified transmission line linear model with linear decay } \\
\text { with height) [9] }\end{array}$ & $\left(1-\frac{z^{\prime}}{H}\right.$ & $v_{f}$ \\
\hline $\begin{array}{l}\text { MTLE (modified transmission line model with exponential decay } \\
\text { with height) [9] }\end{array}$ & $\exp \left(-\frac{z}{\lambda}\right.$ & $v_{f}$ \\
\hline $\begin{array}{l}\text { MTLD (modified transmission line model with current distortion) } \\
{[20,21]}\end{array}$ & {$\left[1-\exp \left(-\frac{t-\left(z^{\prime} / v\right)}{\tau}>\right.\right.$} & $v_{f}$ \\
\hline
\end{tabular}

(1) The lightning channel is assumed to be vertical without any branches.

(2) The ground conductivity is assumed to be infinite.

\section{Return Stroke Current}

The return stroke currents at the channel base (ground surface) and at different heights along a lightning channel can be simulated using current functions and current models, respectively. In this study, the sum of two Heidler current functions $[22,23]$ is used to simulate the channel-base current as expressed by the following equation:

$$
\begin{aligned}
i(0, t)=\left[\frac{i_{01}}{\eta_{1}}\right. & \frac{\left(t / \Gamma_{11}\right)^{n_{1}}}{1+\left(t / \Gamma_{11}\right)^{n_{1}}} \exp \left(\frac{-t}{\Gamma_{12}}\right) \\
& \left.+\frac{i_{02}}{\eta_{2}} \frac{\left(t / \Gamma_{21}\right)^{n_{2}}}{1+\left(t / \Gamma_{21}\right)^{n_{2}}} \exp \left(\frac{-t}{\Gamma_{22}}\right)\right],
\end{aligned}
$$

where $i_{01} / i_{02}$ is the current amplitude of first/second Heidler function in (1), $\Gamma_{11} / \Gamma_{12}$ is the front time constant of first/second Heidler function in (1), $\Gamma_{21} / \Gamma_{22}$ is the decay-time constant in first/second Heidler function in (1), and $n_{1}, n_{2}$ are the exponents $(2 \sim 10)$

$$
\begin{aligned}
& \eta_{1}=\exp \left[-\left(\frac{\Gamma_{11}}{\Gamma_{12}}\right)\left(n_{1} \times \frac{\Gamma_{12}}{\Gamma_{11}}\right)^{1 / n_{1}}\right], \\
& \eta_{2}=\exp \left[-\left(\frac{\Gamma_{21}}{\Gamma_{22}}\right)\left(n_{2} \times \frac{\Gamma_{22}}{\Gamma_{21}}\right)^{1 / n_{2}}\right] .
\end{aligned}
$$

The general form of the engineering current models is considered in this study to cover a wide range of current models as given by (3). Table 1 shows the constant factors of some common engineering current models, where $H$ is the cloud height, $\lambda$ is the decay factor, and $\lambda_{P}$ is the attenuation factor of the peak $[9,20,21]$. It should be mentioned that the MTLE (Modified Transmission Line current model with Exponential decay factor) current model was used for the simulation of electromagnetic fields; however, the proposed method can support a wide range of current models based on (3) $[20,21,24]$

$$
I\left(z^{\prime}, t\right)=I\left(0, t-\frac{z^{\prime}}{v}\right) \times P\left(z^{\prime}\right) \times u\left(t-\frac{z^{\prime}}{v_{f}}\right),
$$

where $z^{\prime}$ is temporary charge height along lightning channel, $I\left(z^{\prime}, t\right)$ is current distribution along lightning channel at any height $z^{\prime}$ and any time $t, I(0, t)$ is the channel-base current, $P\left(z^{\prime}\right)$ is attenuation height dependent factor, $v$ is the currentwave propagation velocity, $v_{f}$ is upward propagating front velocity, and $u$ is Heaviside function defined as

$$
u\left(t-\frac{z^{\prime}}{v_{f}}\right)= \begin{cases}1, & \text { for } t \geq \frac{z^{\prime}}{v_{f}} \\ 0, & \text { for } t<\frac{z^{\prime}}{v_{f}} .\end{cases}
$$

\section{The Return Stroke Velocity}

Several studies have measured subsequent return stroke velocities and they indicate that the return stroke velocity is a height-dependent variable as expressed by a typical function of velocity profile given in (5) [17]. Table 2 illustrates the unknown variables in (5) for a number of current peaks in the range $3-30 \mathrm{kA}$

$$
\begin{aligned}
& v\left(z^{\prime}\right) \\
& =\left\{\begin{array}{lc}
v_{1}+\left(\frac{v_{2}}{2}\right)\left\{2-\exp \left(\frac{-\left(z^{\prime}-1\right)}{\lambda_{1}}\right)-\exp \left(\frac{-\left(z^{\prime}-1\right)}{\lambda_{2}}\right)\right\}, \\
1 \leq z^{\prime} \leq 50 \\
v_{3} \exp \left(\frac{-z^{\prime}}{\lambda_{3}}\right)-v_{4} \exp \left(\frac{-z^{\prime}}{\lambda_{4}}\right), & z^{\prime} \geq 50 .
\end{array}\right.
\end{aligned}
$$

Furthermore, the velocity profiles along a lightning channel for a number of current peaks are illustrated in Figure 1 where the initial parameters are obtained from Table 2.

Figure 2 illustrates the average and maximum values of the velocities of different lightning channels based on the velocity profiles from Figure 1 . Figure 2 shows that, by increasing the current peak, the maximum value of the velocity is increased while the average velocity along the channel has an increasing trend against an increasing current peak up to $21 \mathrm{kA}$. This increasing trend can be seen again in the current peak ranges from $24 \mathrm{kA}$ to $30 \mathrm{kA}$. It should be mentioned that the average values were calculated in first $500 \mathrm{~m}$ of channel as an effective part for the peak of electromagnetic field components. 
TABLE 2: The parameters of return stroke velocity profile [17].

\begin{tabular}{lcccccccc}
\hline$I_{p}(\mathrm{kA})$ & $v_{1}\left(\times 10^{8}\right)$ & $v_{2}\left(\times 10^{8}\right)$ & $v_{3}\left(\times 10^{8}\right)$ & $v_{4}\left(\times 10^{8}\right)$ & $\lambda_{1}$ & $\lambda_{2}$ & $\lambda_{3}$ & $\lambda_{4}$ \\
\hline 3 & 0.72 & 1.18 & 0.19 & 1.71 & 1.8 & 6.2 & 400 & 900 \\
4 & 0.78 & 1.23 & 0.201 & 1.81 & 1.6 & 6.6 & 120 & 1200 \\
6 & 0.86 & 1.29 & 0.86 & 1.29 & 1.6 & 6.8 & 370 & 2200 \\
9 & 0.95 & 1.34 & 0.687 & 1.60 & 1.4 & 7.4 & 320 & 2000 \\
12 & 1.02 & 1.35 & 0.711 & 1.66 & 1.4 & 7.4 & 400 & 2100 \\
15 & 1.07 & 1.37 & 0.488 & 1.95 & 1.2 & 8.0 & 330 & 2000 \\
18 & 1.12 & 1.36 & 0.496 & 1.98 & 1.2 & 7.8 & 400 & 2100 \\
21 & 1.16 & 1.36 & 0.504 & 2.02 & 1.2 & 8.0 & 400 & 2200 \\
24 & 1.2 & 1.34 & 0.254 & 1.29 & 1.2 & 7.6 & 340 & 2100 \\
27 & 1.23 & 1.34 & 0.257 & 1.31 & 1.2 & 7.8 & 400 & 2100 \\
30 & 1.26 & 1.33 & 0.259 & 1.33 & 1.2 & 7.8 & 400 & 2200 \\
\hline
\end{tabular}

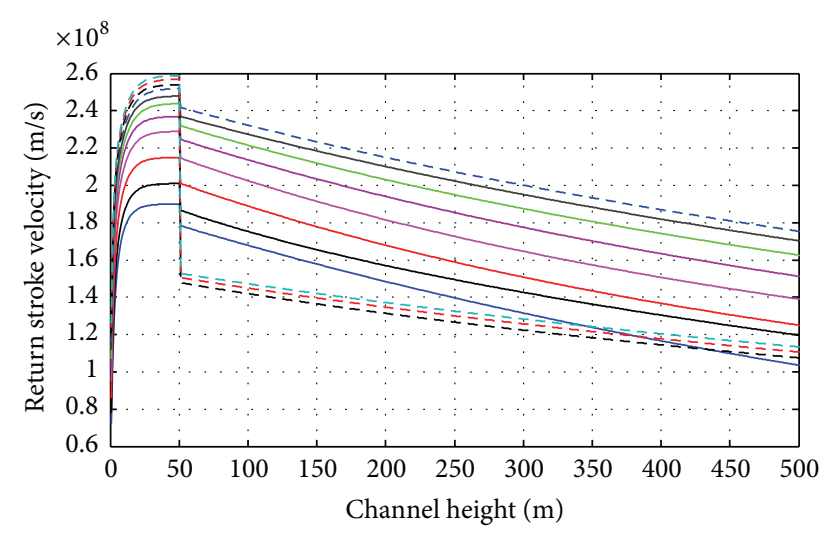

$$
\begin{array}{rlrl}
-I_{p} & =3 \mathrm{kA} & -I_{p} & =18 \mathrm{kA} \\
-I_{p} & =4 \mathrm{kA} & --I_{p} & =21 \mathrm{kA} \\
-I_{p} & =6 \mathrm{kA} & --I_{p}=24 \mathrm{kA} \\
-I_{p} & =9 \mathrm{kA} & --I_{p}=27 \mathrm{kA} \\
-I_{p} & =12 \mathrm{kA} & -\cdots I_{p}=30 \mathrm{kA} \\
I_{p} & =15 \mathrm{kA} & &
\end{array}
$$

FIGURE 1: The velocity profiles for different lightning channels.

\section{The Proposed Electromagnetic Field Expressions}

In order to evaluate the electromagnetic fields due to a lightning channel with variable velocities along the channel, Maxwell's equations are presented in (6) to (9) as follows $[8,13,25]$ :

$$
\begin{gathered}
\nabla \times \vec{E}=-\frac{\partial \vec{B}}{\partial t}, \\
\nabla \times \vec{H}=\vec{J}+\frac{\partial \vec{D}}{\partial t}, \\
\nabla \cdot \vec{D}=\rho_{v}, \\
\nabla \cdot \vec{B}=0,
\end{gathered}
$$

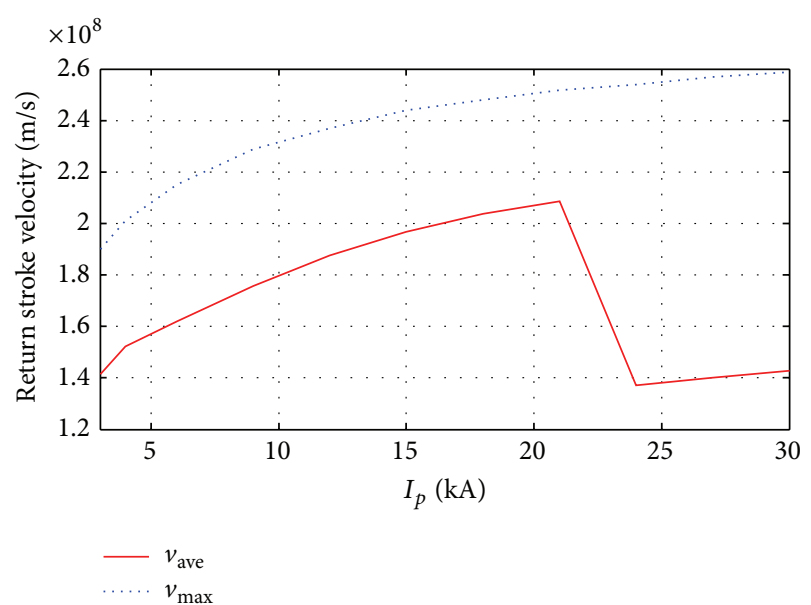

FIGURE 2: The behavior of $v_{\text {ave }}$ and $v_{\max }$ versus current peak changes.

where $\vec{B}$ is the magnetic flux density, $\vec{H}$ is the magnetic field, $\vec{E}$ is the electric field, $\vec{J}$ is the current density, $\vec{D}$ is the electric flux density, and $\rho_{v}$ is the free charge density.

The magnetic flux density can be expressed in terms of the vector potential $(\vec{A})$ as given by the following equation $[10]$ :

$$
\vec{B}=\nabla \times \vec{A} .
$$

The relation between $\vec{B}, \vec{H}$ and $\vec{D}, \vec{E}$ can be expressed, respectively, by the following equations:

$$
\begin{aligned}
\vec{B} & =\mu \vec{H}, \\
\vec{D} & =\varepsilon \vec{E} .
\end{aligned}
$$

Also, (7) can be converted to (13) when (11) and (12) are substituted into (7). By substituting (10) into (6), (6) becomes (14)

$$
\begin{gathered}
\nabla \times \vec{B}=\mu \vec{J}+\mu \varepsilon \frac{\partial \vec{E}}{\partial t}, \\
\nabla \times \vec{E}=-\frac{\partial \vec{B}}{\partial t}=-\frac{\partial(\nabla \times \vec{A})}{\partial t} .
\end{gathered}
$$


Therefore, (14) can be expressed by (15)

$$
\begin{gathered}
\nabla \times\left(\vec{E}+\frac{\partial \vec{A}}{\partial t}\right)=0, \\
\vec{E}+\frac{\partial \vec{A}}{\partial t}=-\nabla v_{e},
\end{gathered}
$$

where $v_{e}$ is the electric scalar potential.

Also, by substituting (10) into (13), the vector potential can be given by the following equations:

$$
\begin{gathered}
\nabla \times \nabla \times \vec{A}=\nabla(\nabla \cdot \vec{A})-\nabla^{2} \vec{A}=\mu \vec{J}+\mu \varepsilon \frac{\partial \vec{E}}{\partial t} \\
\nabla(\nabla \cdot \vec{A})-\nabla^{2} \vec{A}=\mu \vec{J}-\mu \varepsilon \frac{\partial\left(\nabla v_{e}\right)}{\partial t}-\mu \varepsilon \frac{\partial^{2} \vec{A}}{\partial t^{2}}
\end{gathered}
$$

Therefore, (17) can be converted to the following equation:

$$
\nabla^{2} \vec{A}-\mu \varepsilon \frac{\partial^{2} \vec{A}}{\partial t^{2}}=-\mu \vec{J}+\nabla\left(\nabla \cdot \vec{A}+\mu \varepsilon \frac{\partial v_{e}}{\partial t}\right)
$$

According to Lorentz's gauge, the relation between potential vector and scalar potential can be obtained from the following equation [26]:

$$
\nabla \cdot \vec{A}=-\mu \varepsilon \frac{\partial v_{e}}{\partial t}
$$

By substituting (19) into (18) and using free space conditions $\left(\mu=\mu_{0}, \varepsilon=\varepsilon_{0}\right)$, the vector potential can be expressed by the following equation:

$$
\nabla^{2} \vec{A}-\mu_{0} \varepsilon_{0} \frac{\partial^{2} \vec{A}}{\partial t^{2}}=-\mu_{0} \vec{J}
$$

The solution of (20) can be obtained by considering Figure 3 where an infinitesimal current source is located in space by position $\overrightarrow{r^{\prime}}$ from the origin. Also, an observation point (the point at which $\vec{A}$ is to be evaluated) is located in space at point $P$ and $\vec{r}$ is a vector from the origin to the observation point. Hence $\vec{R}=\vec{r}-\overrightarrow{r^{\prime}}$.

The infinitesimal current source can be divided into three current elements as follows:

(1) volume current element $\left(\vec{J}_{i} d v^{\prime}\right)$,

(2) surface current element $\left(\vec{K} d S^{\prime}\right)$,

(3) line current element $\left(\vec{I} d L^{\prime}\right)$, where $\overrightarrow{J_{i}}, \vec{K}$, and $\vec{I}$ are the volume current, the surface current, and the line current densities, respectively. Hence, the solution of (20) will produce the following equation:

$$
\begin{aligned}
& d \vec{A}=\frac{\mu_{0}\left[\overrightarrow{J_{i}}\right] d v^{\prime}}{4 \pi \mid \vec{r}-\overrightarrow{r^{\prime} \mid}}, \\
& d \vec{A}=\frac{\mu_{0}[\vec{K}] d S^{\prime}}{4 \pi \mid \vec{r}-\overrightarrow{r^{\prime} \mid}}, \\
& d \vec{A}=\frac{\mu_{0}[\vec{I}] d L^{\prime}}{4 \pi \mid \vec{r}-\overrightarrow{r^{\prime} \mid}} .
\end{aligned}
$$

Moreover, the geometry of a lightning channel with variable velocity values along the channel is illustrated in Figure 4.

Therefore, the derivative of the potential vector can be expressed by (22) assuming that the lightning channel is perpendicular to the ground surface along the $z$-axis

$$
\overrightarrow{d A}=\frac{\mu_{0} i\left(z^{\prime}, t_{n}-R\left(z^{\prime}\right) / c\right) d z^{\prime}}{4 \pi R\left(z^{\prime}\right)}
$$

where $\Delta h$ is the channel height step, $z^{\prime}=n \Delta h, n$ is the number of height steps along lightning channel $\left(1,2, \ldots, n_{\max }\right), v_{n}$ is the return stroke velocity in each per unit of lightning channel,

$$
\begin{gathered}
t_{n}=\sum_{i=1}^{n} \frac{\Delta h}{v_{i}}+\frac{\sqrt{(n \Delta h)^{2}+r^{2}}}{c}, \\
R\left(z^{\prime}=n \Delta h\right)=\sqrt{(n \Delta h)^{2}+r^{2}} \\
i\left(z^{\prime}, t_{n}-\frac{R\left(z^{\prime}\right)}{c}\right) \\
=P\left(z^{\prime}=n \Delta h\right) \times i\left(0, t_{n}-\sum_{i=1}^{n} \frac{\Delta h}{v_{i}}-\frac{\sqrt{(n \Delta h)^{2}+r^{2}}}{c}\right),
\end{gathered}
$$

and $c$ is speed of light in free space.

By applying (22) to (10) and by using the trapezoid method, the magnetic flux density can be evaluated as follows [27, 28]:

$$
B_{\varphi}^{n}= \begin{cases}-10^{-7} \times \Delta h \sum_{j=1}^{n} F_{1}(j), & n>0 \\ 0, & n=0\end{cases}
$$


where

$$
\begin{aligned}
& F_{1}(j) \\
& \left\{\begin{aligned}
k \times\left[\frac{P(\Delta h)}{\sqrt{\Delta h^{2}+r^{2}}}\right. & d\left\{i\left(0, t_{n}-\Delta h / v_{1}-\sqrt{\Delta h^{2}+r^{2}} / c\right)\right\} \\
& \times \frac{d r}{-} \times(\times P(\Delta h) \\
& \times i\left(0, t_{n}-\frac{\Delta h}{v_{1}}-\frac{\sqrt{\Delta h^{2}+r^{2}}}{c}\right) \\
& \left.\times\left[\Delta h^{2}+r^{2}\right]^{-3 / 2}\right] \\
+ & {\left[\frac{1}{r} \times \frac{d\left\{i\left(0, t_{n}-r / c\right)\right\}}{d r}-\frac{i\left(0, t_{n}-r / c\right)}{r^{2}}\right], }
\end{aligned}\right. \\
& =\left\{\begin{array}{c}
k \times\left[\frac{P(j \Delta h)}{\sqrt{(j \Delta h)^{2}+r^{2}}}\right. \\
\times d\left\{i \left(0, t_{n}-\sum_{i=1}^{j} \frac{\Delta h}{v_{i}}\right.\right. \\
\left.\left.-\frac{\sqrt{(j \Delta h)^{2}+r^{2}}}{c}\right)\right\} \times(d r)^{-1}
\end{array}\right. \\
& -r \times P(j \Delta h) \\
& \times i\left(0, t_{n}-\sum_{i=1}^{j} \frac{\Delta h}{v_{i}}-\frac{\sqrt{(j \Delta h)^{2}+r^{2}}}{c}\right) \\
& \left.\times\left[(j \Delta h)^{2}+r^{2}\right]^{-3 / 2}\right], \\
& k= \begin{cases}1, & j=n, \\
2, & j \neq n .\end{cases}
\end{aligned}
$$

Furthermore, the derivative of the vertical electric field with respect to time and the vertical electric field expressions are proposed by (26) and (27), respectively, where (24) is substituted into (13)

$$
\begin{gathered}
\frac{d E_{z}^{n}}{d t}= \begin{cases}\frac{-\Delta h}{4 \pi r \varepsilon_{0}} \sum_{j=1}^{n} \frac{d\left[r F_{1}(j)\right]}{d r}, & n>0, \\
0, & n=0,\end{cases} \\
E_{z}^{n}= \begin{cases}\frac{-\Delta h}{4 \pi r \varepsilon_{0}} \sum_{s=1}^{n} k^{\prime} \sum_{j=1}^{s} \frac{d\left[r F_{1}(j)\right]}{d r}, & n>0, \\
0, & n=0,\end{cases}
\end{gathered}
$$

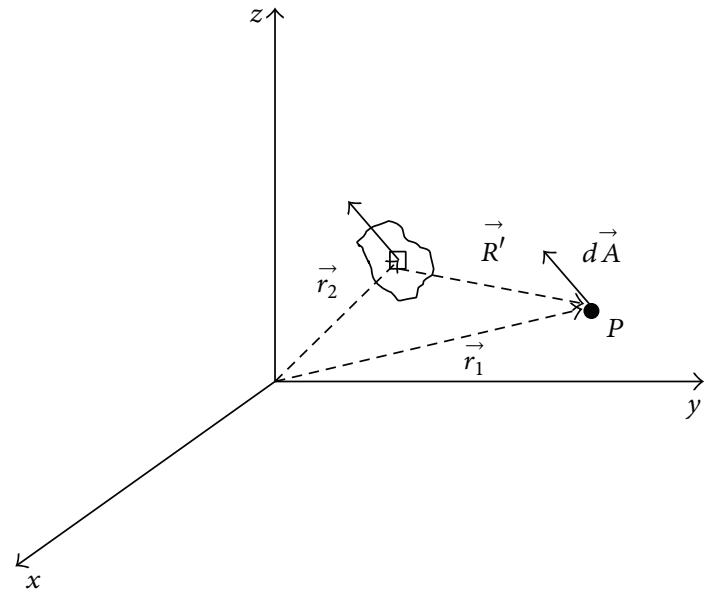

FIGURE 3: Geometry of an observation point with respect to current source.

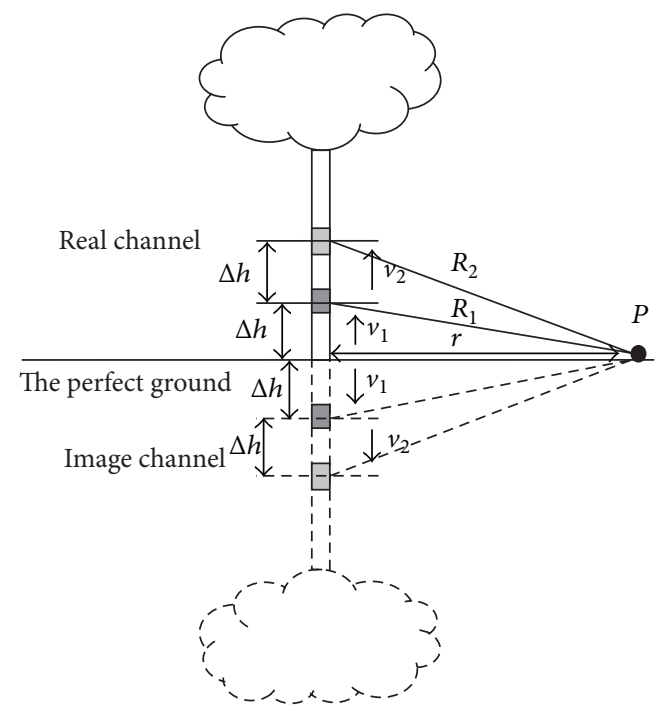

FIGURE 4: The geometry of problem.

where

$$
k^{\prime}=\left\{\begin{array}{cc}
\frac{1}{2}\left[\frac{\Delta h}{v_{1}}+\frac{\sqrt{\Delta h^{2}+r^{2}}}{c}\right], & s=1, \\
\frac{1}{2}\left[\left(\sum_{i=1}^{s} \frac{\Delta h}{v_{i}}-\sum_{i=1}^{s-1} \frac{\Delta h}{v_{i}}\right)\right. & \\
\left.+\frac{\sqrt{(s \Delta h)^{2}+r^{2}}-\sqrt{([s-1] \Delta h)^{2}+r^{2}}}{c}\right], & s \neq 1 .
\end{array}\right.
$$

In order to simulate the electromagnetic fields associated with a lightning channel, a sample of a measured channel-base current is simulated using the sum of two Heidler functions as shown in Figure 5, whereas the measured current is obtained from a triggered lightning experiment. Table 3 illustrates the evaluated current parameters based on (1) $[29,30]$. 
TABLE 3: The current parameters based on the sum of two Heidler functions.

\begin{tabular}{lccccccc}
\hline $\begin{array}{l}i_{01} \\
(\mathrm{kA})\end{array}$ & $\begin{array}{c}i_{02} \\
(\mathrm{kA})\end{array}$ & $\begin{array}{c}\tau_{11} \\
(\mu \mathrm{s})\end{array}$ & $\begin{array}{c}\tau_{12} \\
(\mu \mathrm{s})\end{array}$ & $\begin{array}{c}\tau_{21} \\
(\mu \mathrm{s})\end{array}$ & $\begin{array}{c}\tau_{22} \\
(\mu \mathrm{s})\end{array}$ & $n_{1}$ & $n_{2}$ \\
\hline 17.793 & 10.753 & 0.434 & 1.775 & 2.611 & 57.64 & 2 & 2 \\
\hline
\end{tabular}

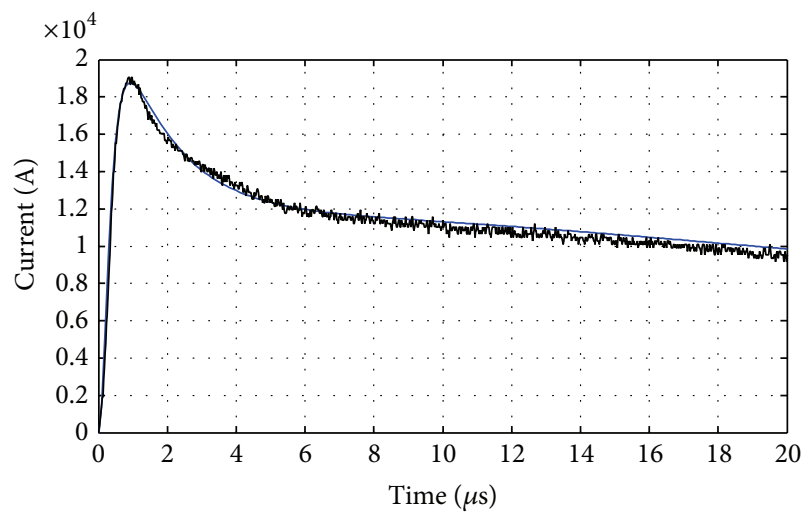

—- Simulated channel base current

_ Measured channel base current

Figure 5: Comparison between simulated and measured channelbase current.

Figure 5 shows that the simulated current is in good agreement with the corresponding measured current. Therefore, the magnetic flux densities and the vertical electric fields based on the variable and constant values of the velocity at $r=$ $15 \mathrm{~m}$ are evaluated based on the proposed method and the simulated fields are compared to the corresponding measured fields as illustrated in Figures 6 and 7, respectively. It should be noted that the constant velocity is set at the average value of the velocity along the lightning channel and the MTLE model is used for the current model. Likewise, the velocity profile for the case of variable velocity is based on (5) with the corresponding parameters that can be obtained from the 7 th row of Table 2.

Figure 6 shows that the simulated magnetic flux density based on the variable values of the velocity is in better agreement with the corresponding measured field compared to the simulated field that is obtained from using a constant value for the velocity. However, this difference is not great. Moreover, the simulated vertical electric field due to the variable values of the velocity is in good agreement with the corresponding measured field as shown in Figure 7, while the simulated vertical electric field based on a constant velocity is not closer to the corresponding measured field. In previous studies, the appropriate average velocity is set as a basic assumption so as to obtain a good agreement between the simulated field and the measured field. This value is usually selected based on trial and error because in order to determine the average velocity, the values of the velocity at different heights along a lightning channel are required and these are based on recording the velocity values at just a few

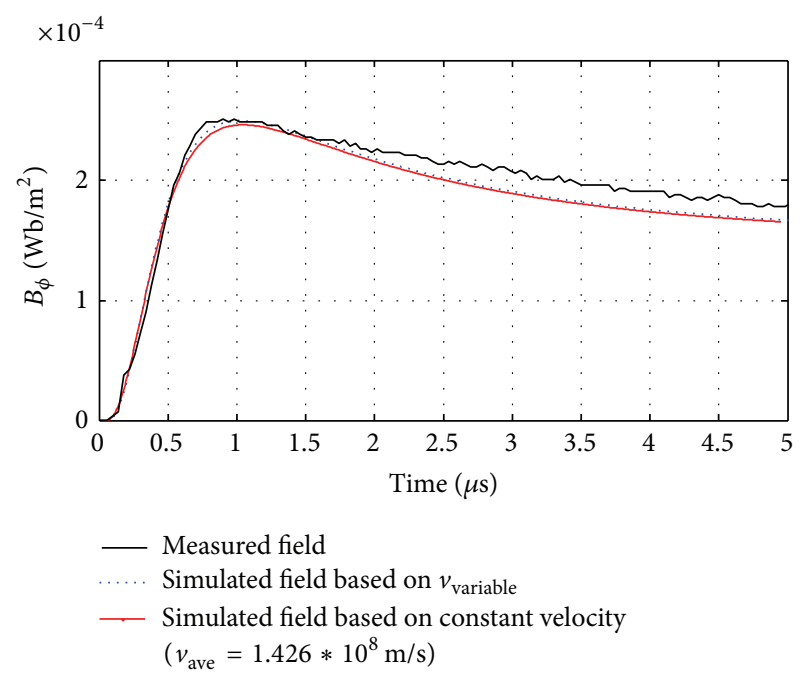

FIGURE 6: Comparison between simulated and measured magnetic flux density at $r=15 \mathrm{~m}$.

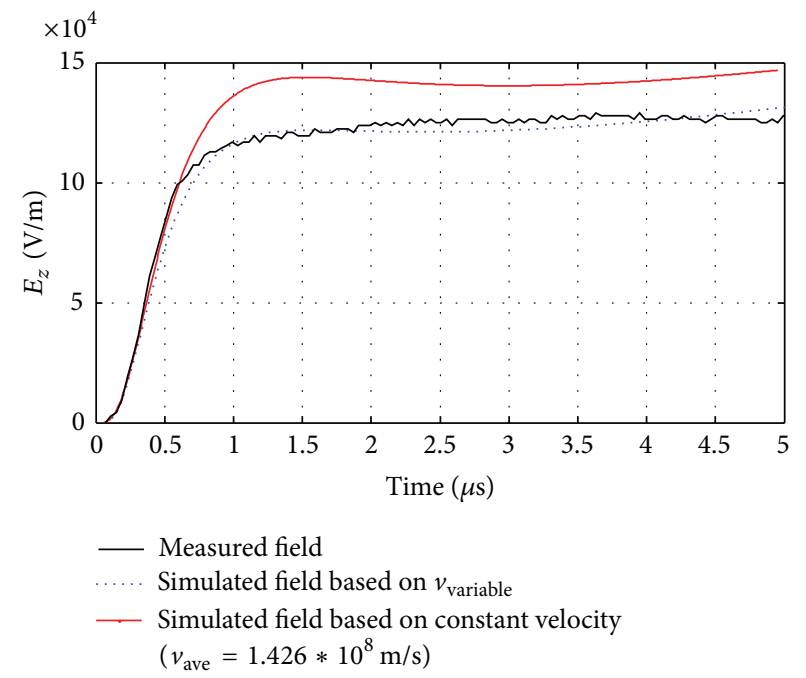

FIGURE 7: Comparison between simulated and measured vertical electric field at $r=15 \mathrm{~m}$.

points along the channel. In the present study, the average value of the velocity is obtained from the velocity function (5).

The simulated $d E_{z} / d t$ for both the constant and variable cases are demonstrated in Figure 8 which shows the peak of $d E_{z} / d t$ due to the variable values of the velocity are lower than the similar values based on a constant velocity. This could be due to changes in the charge heights at different times along the lightning channel while the charge height values are more effective for the integration of current components along a lightning channel. Moreover, the effect of velocity changes on the values of horizontal electric field was considered as shown in Figure 9. Figure 9 illustrates that the effect of velocity changes on the values of horizontal electric fields at closed distances with respect to lightning is not considerable. 


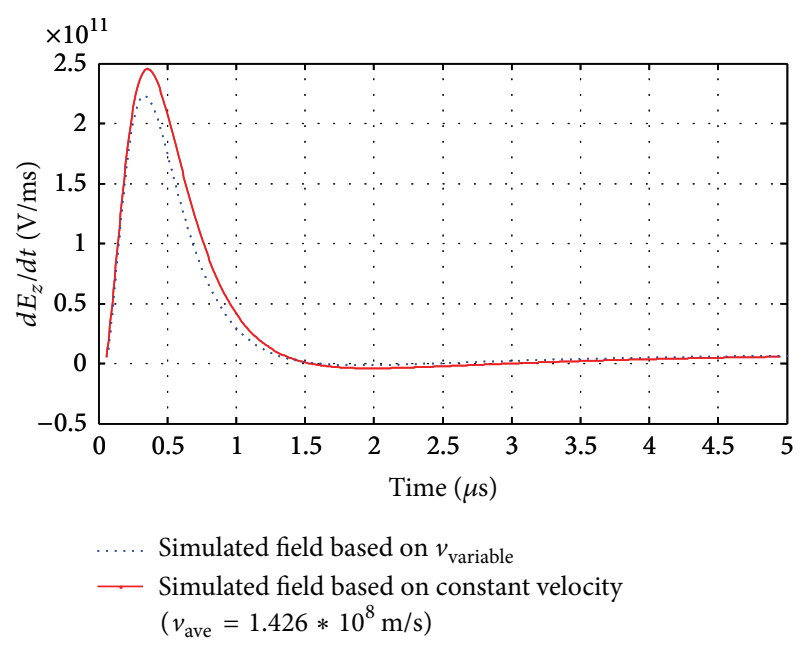

Figure 8: Comparison between simulated and measured $d E_{z} / d t$ at $r=15 \mathrm{~m}$.

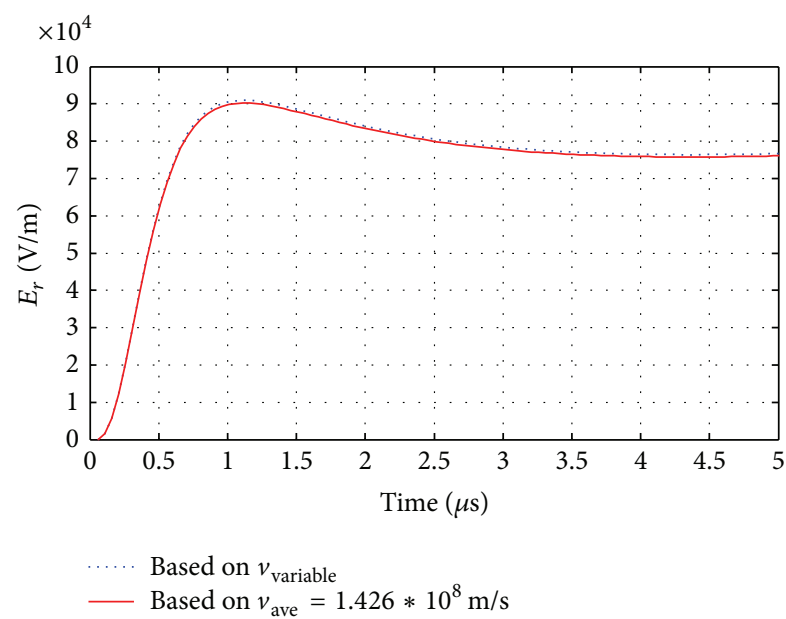

Figure 9: Comparison between simulated horizontal electric fields at $r=15 \mathrm{~m}, z=10 \mathrm{~m}$.

Figures 10, 11, and 12 show the behavior of peak values of magnetic flux density, vertical electric field, and horizontal electric fields versus height changes (observation point), respectively.

The proposed method can consider the different behaviours of the velocity along a lightning channel directly in the time domain without the need to apply any extra conversions. Likewise, the method can support different current functions and the general form of the engineering current models. Moreover, the results show that the simulated fields based on the general function of the velocity are closer to the corresponding measured fields compared to the simulated fields based on the average values of velocity, especially for a vertical electric field.

\section{Conclusion}

In this paper, general electromagnetic field expressions are proposed to consider the variation of velocity along

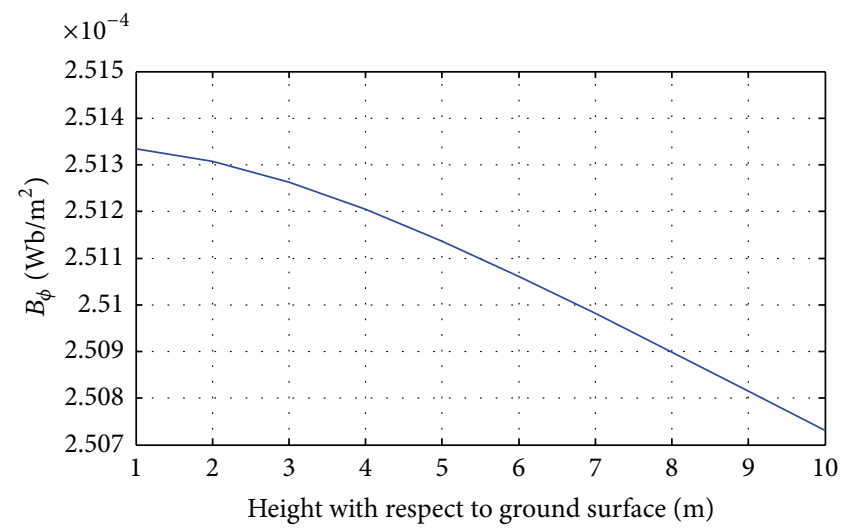

FIGURE 10: Behaviour of magnetic flux density (peak) versus height changes (observation point) at $r=15 \mathrm{~m}$.

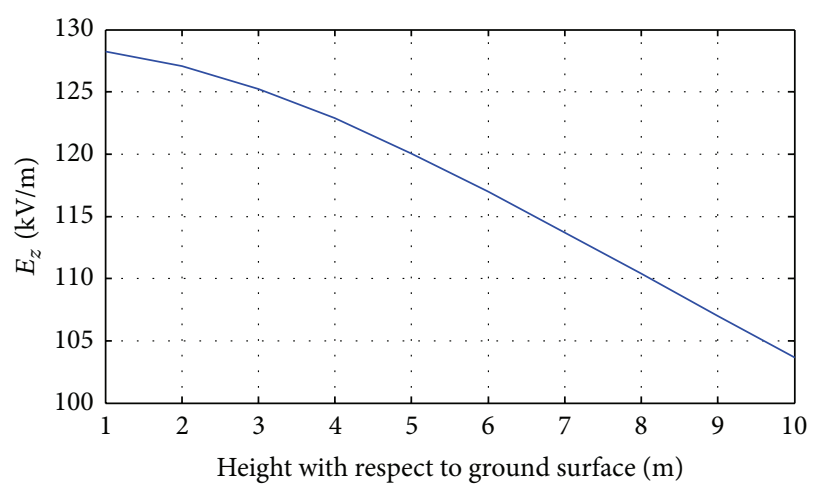

FIGURE 11: Behaviour of vertical electric field (peak) versus height changes (observation point) at $r=15 \mathrm{~m}$.

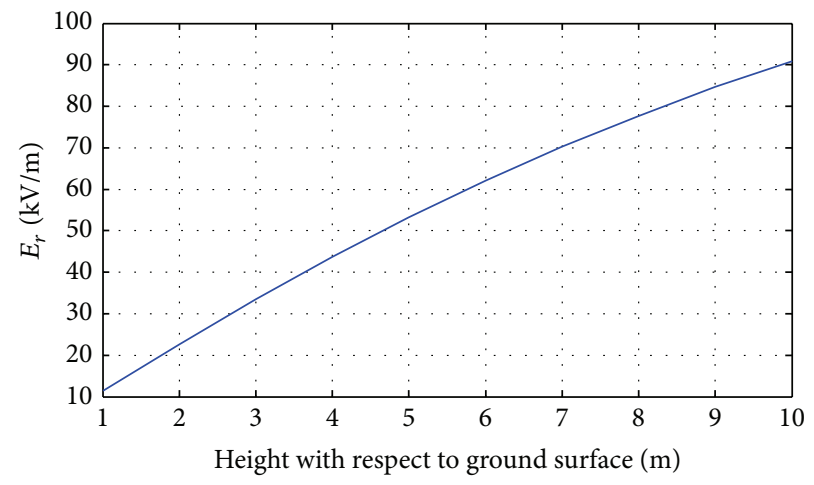

FIGURE 12: Behaviour of horizontal electric field (peak) versus height changes (observation point) at $r=15 \mathrm{~m}$.

a lightning channel directly in the time domain, while the measured values of the velocity show that the velocity is a height-dependent variable which is usually entered into field calculations as a constant value. By the simulation of the velocity behaviour along a lightning channel based on the general velocity function, the proposed method is applied to a sample of measured channel-base current from a triggered lightning experiment and the simulated fields are validated 
using the corresponding measured fields. The results show that the simulated fields are in good agreement with the measured fields. Likewise, the simulated electromagnetic fields based on variable values of the velocity are compared to the corresponding simulated fields based on a constant value for the velocity and the results are discussed accordingly. The proposed method can support different velocity behaviours, current functions, and the general form of the engineering current model directly in the time domain without the need to apply any extra conversions.

\section{Conflict of Interests}

The authors declare that there is no conflict of interests regarding the publication of this paper.

\section{References}

[1] F. Rachidi, M. Rubinstein, S. Guerrieri, and C. A. Nucci, "Voltages induced on overhead lines by dart leaders and subsequent return strokes in natural and rocket-triggered lightning," IEEE Transactions on Electromagnetic Compatibility, vol. 39, no. 2, pp. 160-166, 1997.

[2] F. Rachidi, C. A. Nucci, M. Ianoz, and C. Mazzetti, "Response of multiconductor power lines to nearby lightning return stroke electromagnetic fields," in Proceedings of the 14th IEEE Transmission and Distribution Conference, pp. 294-301, September 1996.

[3] F. Rachidi, C. A. Nucci, M. Ianoz, and C. Mazzetti, "Influence of a lossy ground on lightning-induced voltages on overhead lines," IEEE Transactions on Electromagnetic Compatibility, vol. 38, no. 3, pp. 250-264, 1996.

[4] F. Rachidi, "Formulation of the field-to-transmission line coupling equations in terms of magnetic excitation field," IEEE Transactions on Electromagnetic Compatibility, vol. 35, no. 3, pp. 404-407, 1993.

[5] M. Paolone, C. A. Nucci, E. Petrache, and F. Rachidi, "Mitigation of lightning-induced overvoltages in medium voltage distribution lines by means of periodical grounding of shielding wires and of surge arresters: modeling and experimental validation," IEEE Transactions on Power Delivery, vol. 19, no. 1, pp. 423-431, 2004.

[6] M. Izadi, M. Z. A. Ab Kadir, C. Gomes, and W. F. Wan Ahmad, "An analytical second-fdtd method for evaluation of electric and magnetic fields at intermediate distances from lightning channel," Progress in Electromagnetics Research, vol. 110, pp. 329-352, 2010.

[7] M. Izadi, M. Z. A. A. Ab Kadir, C. Gomes, and W. F. W. Ahmad, "Numerical expressions in time domain for electromagnetic fields due to lightning channels," International Journal of Applied Electromagnetics and Mechanics, vol. 37, no. 4, pp. 275-289, 2011.

[8] M. Izadi, M. Z. Ab Kadir, C. Gomes, and W. F. H. Wan Ahmad, "Analytical expressions for electromagnetic fields associated with the inclined lightning channels in the time domain," Electric Power Components and Systems, vol. 40, no. 4, pp. 414438, 2012.

[9] C. A. Nucci, "Lightning-induced voltages on overhead power lines. Part I: return stroke current models with specified channel-base current for the evaluation of the return stroke electromagnetic fields," Electra, vol. 161, pp. 75-102, 1995.
[10] R. Thottappillil and V. Rakov, "Review of three equivalent approaches for computing electromagnetic fields from an extending lightning discharge," Journal of Lightning Research, vol. 1, pp. 90-110, 2007.

[11] R. Thottappillil, V. A. Rakov, and N. Theethayi, "Expressions for far electric fields produced at an arbitrary altitude by lightning return strokes," Journal of Geophysical Research D: Atmospheres, vol. 112, no. 16, Article ID D16102, 2007.

[12] M. Rubinstein and M. A. Uman, "Methods for calculating the electromagnetic fields from a known source distribution: application to lightning," IEEE Transactions on Electromagnetic Compatibility, vol. 31, no. 2, pp. 183-189, 1989.

[13] M. Izadi, M. Z. A. Ab Kadir, C. Gomes, and W. F. Wan Ahmad, "Evaluation of the electromagnetic fields due to lightning channel with respect to the striking angle," International Review of Electrical Engineering, vol. 6, no. 2, pp. 1013-1023, 2011.

[14] V. Rakov, "lightning return stroke speed," Journal of Lightning Research, vol. 1, 2007.

[15] D. Wang, N. Takagi, T. Watanabe, V. A. Rakov, and M. A. Uman, "Observed leader and return-stroke propagation characteristics in the bottom $400 \mathrm{~m}$ of a rocket-triggered lightning channel," Journal of Geophysical Research D: Atmospheres, vol. 104, no. 12, pp. 14369-14376, 1999.

[16] R. C. Olsen III, D. M. Jordan, V. A. Rakov, M. A. Uman, and N. Grimes, "Observed one-dimensional return stroke propagation speeds in the bottom $170 \mathrm{~m}$ of a rocket-triggered lightning channel," Geophysical Research Letters, vol. 31, no. 16, 2004.

[17] V. Cooray, The lightning Flash, IET Press, 2003.

[18] C. E. R. Bruce and R. H. Golde, "The lightning discharge," The Journal of the Institute of Electrical Engineers Part 2, vol. 88, 1941.

[19] F. Heidler, "Travelling current source model for LEMP calculation," in Proceedings of the 6th Symposium and Technical Exhibition on Electromagnetic Compability, Zürich, Switzerland, 1985.

[20] Y. Baba and M. Ishii, "Lightning return-stroke model incorporating current distortion," IEEE Transactions on Electromagnetic Compatibility, vol. 44, no. 3, pp. 476-478, 2002.

[21] Y. Baba, S. Miyazaki, and M. Ishii, "Reproduction of lightning electromagnetic field waveforms by engineering model of return stroke," IEEE Transactions on Electromagnetic Compatibility, vol. 46, no. 1, pp. 130-133, 2004.

[22] F. Heidler, "Analytische Blitzstromfunktion zur LEMP- Berechnung," in Conference Proceedings: ICLP '85, 18th International Conference on Lightning Protection, Hotel Hilton, Munich, Federal Republic of Germany, September 16-20, 1985, 1985.

[23] M. Izadi, M. Z. A. Ab Kadir, C. Gomes, and V. Cooray, "Evaluation of lightning return stroke current using measured electromagnetic fields," Progress in Electromagnetics Research, vol. 130, pp. 581-600, 2012.

[24] V. Rakov and A. Dulzon, "A modified transmission line model for lightning return stroke field calculations," in Proceedings of the 9th International Zurich Symposium on Electromagnetic Compatibility, pp. 229-235, Zurich, Switzerland, 1991.

[25] M. Izadi, M. Z. A. A. Kadir, and C. Gomes, "Evaluation of electromagnetic fields associated with inclined lightning channel using second order FDTD-hybrid methods," Progress in Electromagnetics Research, vol. 117, pp. 209-236, 2011.

[26] R. Nevels and C.-S. Shin, "Lorenz, Lorentz, and the gauge," IEEE Antennas \& Propagation Magazine, vol. 43, no. 3, pp. 70-72, 2001. 
[27] E. Kreyszig, Advanced Engineering Mathematics, Wiley-India, New Delhi, India, 2007.

[28] M. N. O. Sadiku, Numerical Technique in Electromagnetics, CRC Press, New York, NY, USA, 2001.

[29] D. Lovrić, S. Vujević, and T. Modrić, "On the estimation of Heidler function parameters for reproduction of various standardized and recorded lightning current waveshapes," International Transactions on Electrical Energy Systems, vol. 23, no. 2, pp. 290-300, 2013.

[30] S. Vujević, D. Lovrić, and I. Jurić-Grgić, "Least squares estimation of Heidler function parameters," European Transactions on Electrical Power, vol. 21, no. 1, pp. 329-344, 2011. 


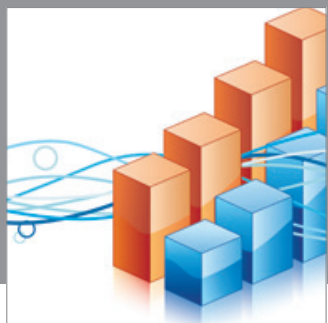

Advances in

Operations Research

mansans

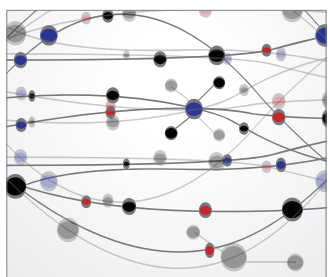

The Scientific World Journal
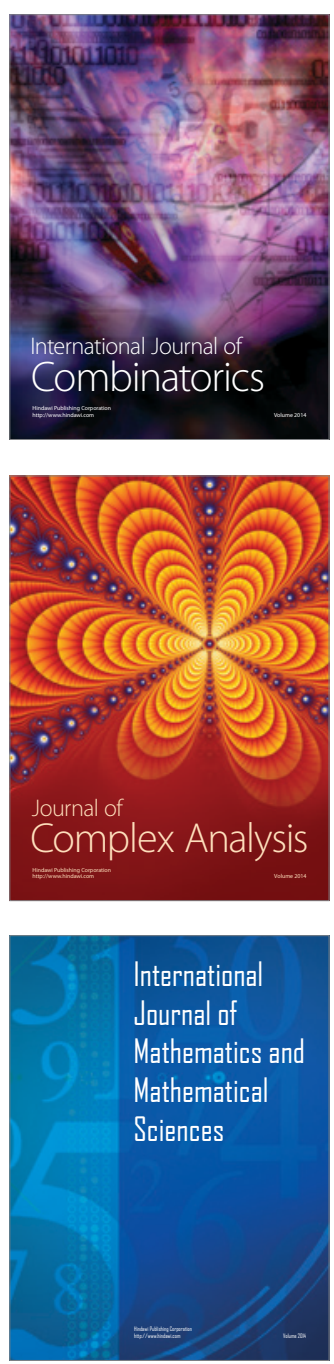
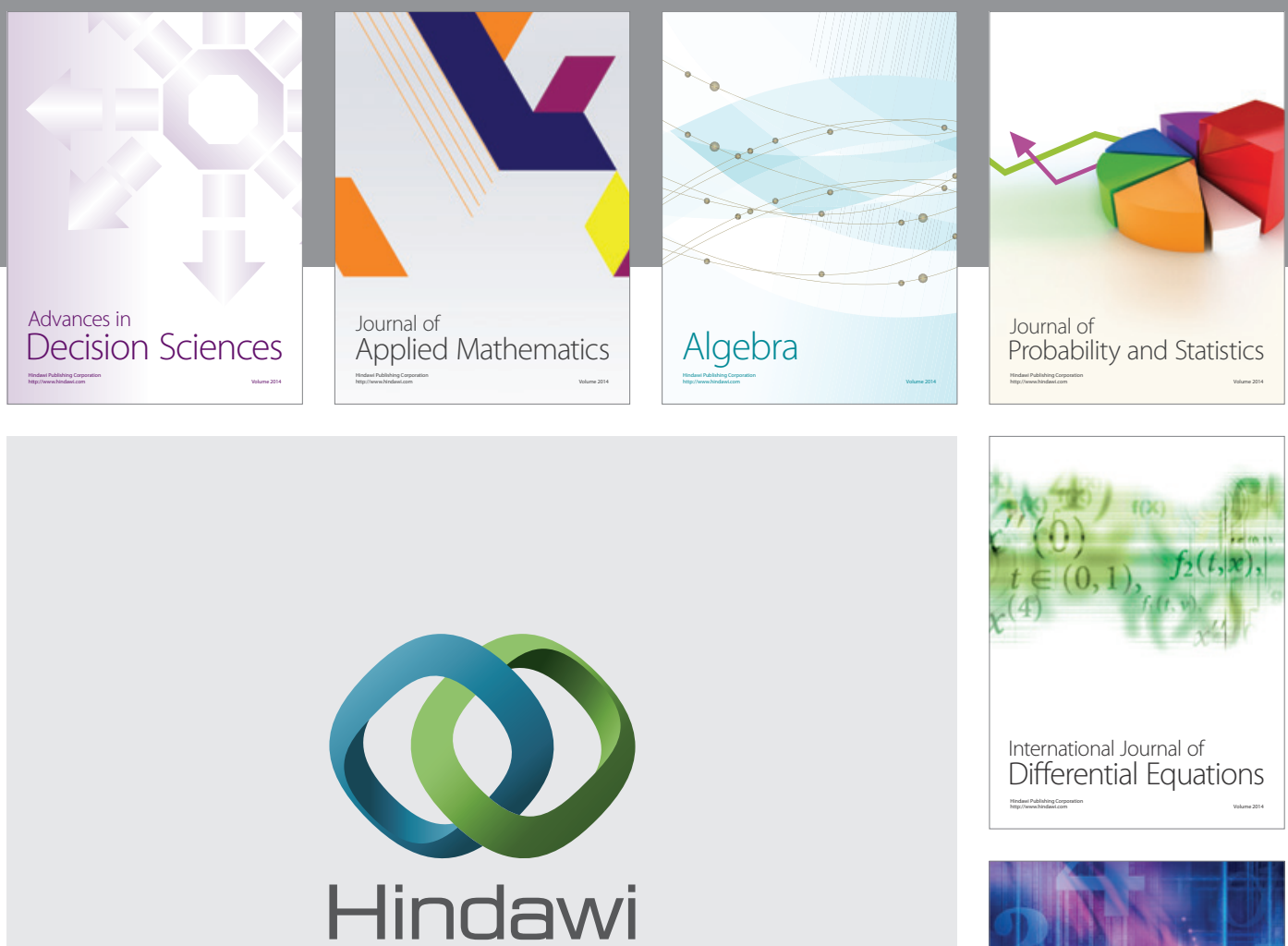

Submit your manuscripts at http://www.hindawi.com
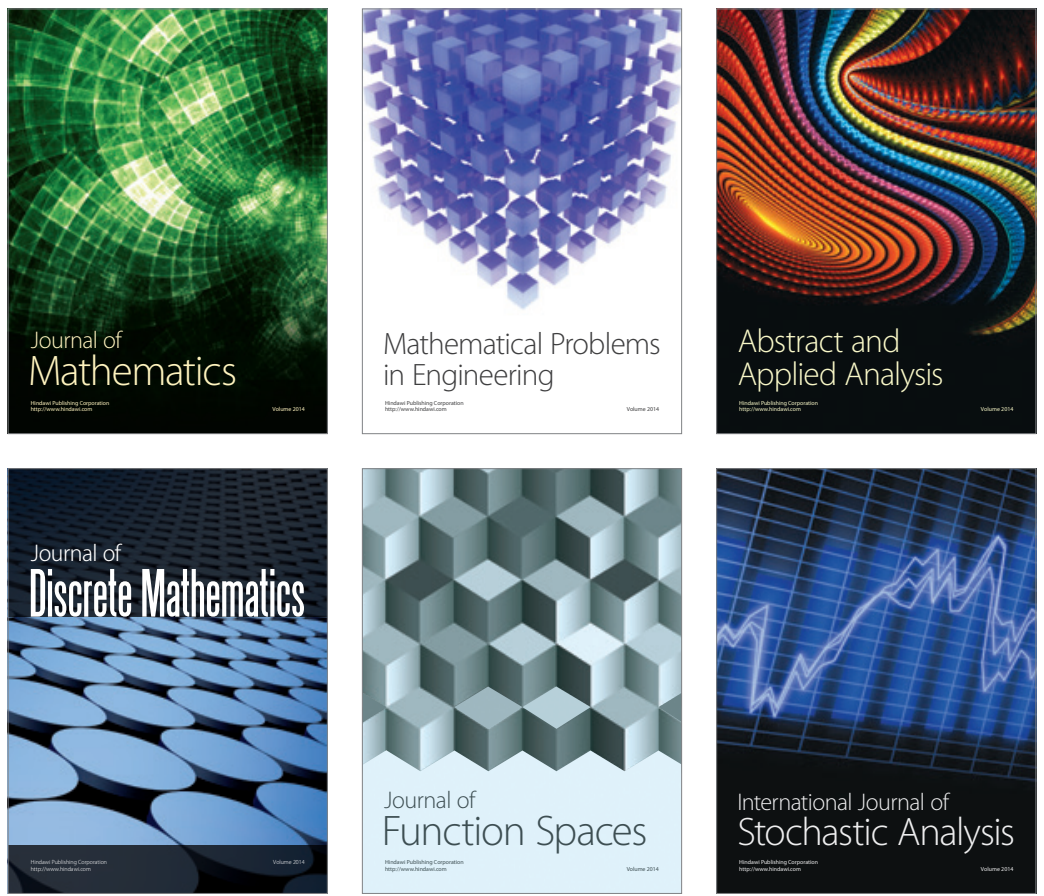

Journal of

Function Spaces

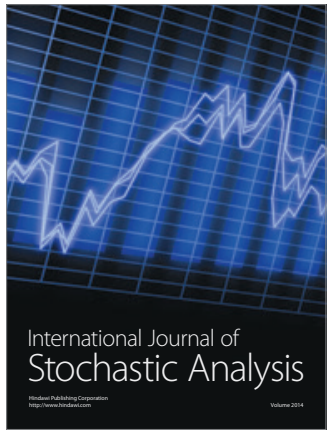

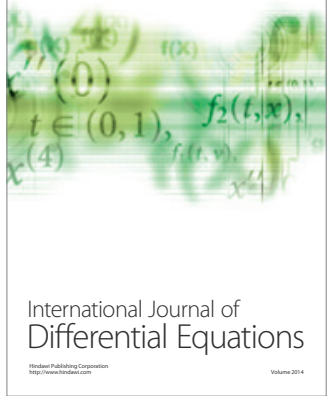
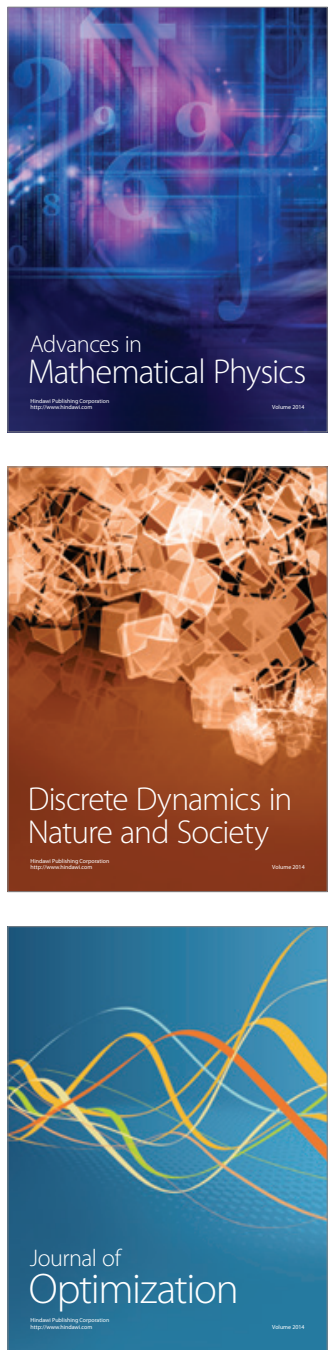